\title{
EFICIÊNCIA HIDROENERGÉTICA EM SISTEMAS DE DISTRIBUIÇÃO DE ÁGUA ${ }^{1}$
}

Hyane Assunção de Araújo ${ }^{2}$, Universidade Federal do Piauí

\section{RESUMO}

A evolução do consumo de água e energia tem associação direta com o crescimento demográfico e econômico do país. Em contrapartida, nos últimos anos, o Brasil passa por uma crise hídrica proveniente de irregularidades dos regimes pluviométricos, altas temperaturas, entre outros fatores. Além disso, o abastecimento público de água aparece como um dos principais consumidores de energia, principalmente na etapa de bombeamento. $O$ objetivo desse estudo é analisar o sistema de distribuição de água, tendo em vista apontar as oportunidades de redução de custos e consumo de energia elétrica. Trata-se de um estudo teórico, realizado através de pesquisa bibliográfica pautada nos ensinamentos de autores como Gomes (2009), Linhares (2011) e Marrucci (2009), bem como documentos legais, que abrange aspectos do sistema de bombeamento, seus componentes, indicadores de eficiência e medidas de economia hidroenergética. Conclui-se através desta pesquisa que através de uma visão sistêmica sobre os componentes hidráulicos envolvidos nas etapas do sistema de bombeamento é possível reduzir o consumo de energia da infraestrutura hídrica para abastecimento público.

Palavras-chave: Economia. Sistema de bombeamento. Diagnóstico de perdas.

\section{INTRODUÇÃO}

A evolução do consumo de água tem associação direta com o crescimento demográfico e econômico do país. Todavia, os baixos índices de precipitação, altas temperaturas, irregularidades dos regimes pluviométricos, entre outros fatores, contribuíram para uma crise hídrica nacional.

Segundo a Agência Nacional de Águas (ANA) no relatório pleno de Conjuntura dos Recursos Hídricos no Brasil 2018 (2018, p.53) “os principais usos da água no Brasil são para irrigação, abastecimento humano e animal, industrial, geração de energia, mineração, agricultura, navegação, turismo e lazer".

\footnotetext{
${ }^{1}$ Trabalho apresentado no Congresso Brasileiro Ciência e Sociedade (CBCS 2019), promovido pelo Centro Universitário Santo Agostinho, de 03 a 05 de outubro de 2019, em Teresina-PI.

2 Pós-graduada, Engenharia Elétrica, hyane@ufpi.edu.br
} 


\section{conghESSOCIENCIAESOCIEDADE

Em particular, o abastecimento público de água, que até há poucos anos era feito por meio de fontes limpas captadas nas encostas e trazidas às comunidades pela ação da gravidade, atualmente depende praticamente na totalidade de bombeamento. O uso de bombas de água tornou-se indispensável e, como consequência, também o uso da energia elétrica para o acionamento dos motores que fazem funcionar as bombas (CENTRAIS ELÉTRICAS BRASILEIRAS, 2005, p.13).

Vislumbra-se que para abastecer a infraestrutura hídrica, principalmente nos sistemas de bombeamento, demanda-se muita eletricidade, sendo uma parte consumida e outra perdida em diversos pontos durante o processo (BID, 2011).

No Brasil, em 2015, as despesas com energia elétrica dos prestadores de serviço de saneamento atingiram $\mathrm{R} \$$ 5,14 bilhões, tendo sido consumidos $11,0 \mathrm{TWh}$ com abastecimento de água (BRASIL, 2017). Essa realidade aliada à preocupação com a proteção dos recursos hídricos e energéticos do planeta, torna imprescindível a busca por mecanismos capazes de tornar os sistemas de bombeamento mais eficientes, seja por meio do aumento do rendimento dos equipamentos, seja pela diminuição das perdas ao longo do sistema.

O objetivo desse trabalho é analisar o sistema de distribuição de água, tendo em vista apontar as oportunidades de redução de custos e consumo de energia elétrica. Em face disso, o presente trabalho levanta a seguinte questão: como ter eficiência hidroenergética em sistemas de bombeamento de água? Para responder tal questionamento, foi realizada uma revisão bibliográfica.

\section{METODOLOGIA}

No processo investigativo se utilizou-se a pesquisa bibliográfica, pois segundo Gil (2002), uma de suas funções principais consiste em analisar as diversas posições acerca de determinado problema. Para tanto, foram estudados obras de autores como Go Associados (2018) e Gomes (2009), bem como manuais nacionais, normas internacionais e pesquisas realizadas por órgãos brasileiros, como o Sistema Nacional de Informações sobre Saneamento e ELETROBRÁS/PROCEL, que abordam direta e indiretamente a problemática investigada. 


\section{CONQEESSOC CIENCIAESOCIEDADE

\section{SISTEMAS DE BOMBEAMENTO}

O processo de abastecimento de água das cidades é realizado por sistema composto pelas seguintes etapas: captação, bombeamento, tratamento, armazenagem, distribuição e uso final. Esses componentes seguem o trajeto do fluido (água), desde a captação até os pontos de uso final, e ainda o dimensionamento dos equipamentos, bem como a magnitude do sistema depende do volume requerido pela localidade que ele vai atender.

Em linhas gerais, tem-se que o sistema de captação pode ser um leito de um rio, um reservatório (artificial ou não) ou mesmo um poço artesiano. Já o de bombeamento, pode ser composto por uma ou mais bombas, sendo responsável por, de fato, bombear o fluido até a superfície, para que possa ser aproveitado. Todavia, antes de chegar ao consumidor, este deve passar por uma série de tratamentos para que a água bruta possa ser consumida sem trazer riscos à saúde, indo em sequência para fase de armazenamento e finalmente distribuída aos usuários (GOMES, 2009).

O maior consumo de energia dentro do sistema de abastecimento ocorre no setor de bombeamento devido o motor empregado nas bombas. Além disso, a energia que será consumida por um sistema de bombeamento depende da potência que precisa ser fornecida e do número de horas de funcionamento.

Vale mencionar que ao longo de todo o processo, acontece perdas dos recursos hídricos em decorrências de várias causas como vazamentos, problemas de conectores, erros de medição, consumidores não autorizados, entre outros. Segundo dados do Sistema Nacional de Informações sobre Saneamento - SNIS (2017) apresentados por GO Associados (2019), ao distribuir água para garantir consumo, os sistemas sofrem perdas na distribuição, que na média do país alcançam $38,29 \%$. No Nordeste esse percentual é de 46,25\%.

Outro ponto importante situa-se na redução do consumo final de água, pois implica diretamente na diminuição de custos com saneamento básico. Como acentua ELETROBRÁS/PROCEL (2005, p. 30) “considerando uma perda média de $20 \%$ nos 


\section{CONQEEESSOCIENCIAESOCIEDADE

sistemas de abastecimento do Brasil (valor conservador), a economia de 1 litro de água no consumo final evita a captação, bombeamento e tratamento de 1,25 litro, bem como reduz um litro de tratamento de esgoto".

Desse modo, é preciso incentivar a utilização de equipamentos de baixo consumo de água por parte da população em geral, bem como promover campanhas educativas com orientações para evitar o desperdício desse recurso natural, diminuir o tempo de uso, buscar soluções alternativas como optar por baldes ao invés de mangueira ao lavar o carro ou a calçada, entre outros.

É necessário enfatizar ainda, que a manutenção do sistema é imprescindível para garantir o bom funcionamento dos equipamentos, preservar a vida útil deles e identificar falhas incipientes, evitando assim o comprometimento do abastecimento. Um sistema só é confiável se todos os seus elementos estiverem em boas condições e operando de forma correta.

\section{DIAGNOSTICANDO PONTOS DE PERDAS}

Como já foi mencionado há perdas hidráulicas e elétricas ao longo do sistema de bombeamento, cabe então analisar, de modo separado, tais perdas, de modo a buscar alternativas que contribuam com a redução das mesmas. No que tange às perdas de água, na literatura técnica a metodologia utilizada pelos prestadores e reguladores obedece à proposta pela International Water Association (IWA), que avalia o Balanço Hídrico ao longo do sistema.

O Balanço Hídrico refere-se ao percurso da água ao longo do sistema. A água entra no sistema e durante o processo de distribuição esse volume de água se subdivide em consumo autorizado e perdas. No consumo autorizado considera-se o consumo faturado e estimado, o consumo não faturado proveniente de abastecimento próprio ou caminhão-pipa, e o consumo não medido. Esses dados servem de parâmetro para análise de consumo por unidade consumidora. Nas perdas, incluem-se perdas aparentes (comerciais) como fraudes, erros de medição e falhas de cadastro, 


\section{CONQEEESSOCIENCIAESOCIEDADE

bem como as perdas reais provenientes, em sua maioria, de vazamentos em diferentes pontos do sistema (GO ASSOCIADOS, 2018).

Segundo GO Associados (2018) enquanto as perdas reais afetam diretamente os custos de produção e demanda hídrica, pois o elevado nível dessas perdas sugere uma captação e produção superior ao volume efetivamente demandado, as aparentes impactam de modo direto a receita das empresas, visto que equivalem a volumes produzidos e consumidos, mas não faturados.

Assim como o Balanço Hídrico, há também o Balanço Energético referente ao percurso da energia ao longo do sistema, considerando os pontos de consumo e as perdas. Em linhas gerais, tem-se a energia elétrica fornecida pela companhia de eletricidade, perdas (elétricas, no motor, na bomba e de carga) e vazamentos.

Conforme o BID (2011, p. 40) pontua "um dos maiores pontos de perdas energéticas ocorre na etapa de transformação da energia elétrica em [...] mecânica obtida por meio do sistema de bombeamento e transmitida para o fluido sob a forma de potência manométrica."

O conhecimento dos balanços hídrico e energético, característico deste sistema, contribui para a identificação das perdas que reduzem sua eficiência. Também, fornece um ponto de partida para reconhecer as oportunidades e selecionar e implementar ações de melhorias da eficiência (ELETROBRAS/PROCEL, 2005).

\section{INDICADORES DE EFICIÊNCIA ELETROMECÂNICA NO SISTEMA}

Os indicadores de eficiência eletromecânica nos sistemas de bombeamento se baseiam nas características do conjunto motor-bomba e de ambos os componentes de forma separada, bem como as curvas de comportamento carga-fluxo-rendimento do equipamento de bombeamento.

Inicialmente, é necessário medir os parâmetros elétricos (tensão, corrente, fator de potência, potência ativa e reativa) de modo a determinar a potência de operação e calcular a eficiência dos equipamentos de bombeamento, e os hidráulicos: medição (da vazão à descarga em bombas, da carga de pressão de operação, na sucção 


\section{CONQEEESSOCIENCIAESOCIEDADE

e descarga, do nível dinâmico de suç̧ão e de níveis dos centros dos manômetros na sucção, bem como na descarga) e definição do nível de referência (ELETROBRAS/PROCEL, 2005).

Outra ação muito importante é a medição da temperatura dos equipamentos, como motores, transformadores e instrumentos de controle como disjuntores e chaves de partida. Essa ação ajuda a monitorar o comportamento operacional nos sistemas elétricos e de bombeamento, facilitando a manutenção, que consequentemente identifica falhas incipientes e reduz os custos.

No que se refere ao conjunto motor-bomba, ele é composto basicamente de motor e bombeador. Geralmente, o motor utilizado é um de indução devido ao baixo custo e grande versatilidade. A eficiência é a medida de sua capacidade de transformar a potência elétrica que toma da linha em potência mecânica útil.

Três fatores influenciam na redução da eficiência do motor: em primeiro lugar, o próprio envelhecimento do maquinário ao longo dos anos; em segundo, casos de rebobinagem e as condições desse rebobinamento; e por último, se a tensão de alimentação for diferente daquela da placa.

Em se tratando da bomba, pode ser volumétrica (ou deslocamento positivo) ou centrífuga (ou turbo-bombas), dependendo do seu funcionamento. Os parâmetros hidráulicos mais importantes para o seu dimensionamento são: vazão, altura manométrica, potência e rendimento.

Entende-se como vazão, a quantidade de água que ela retira e impele (recalca) em um tempo determinado. É importante que a vazão consiga atender a população nos diferentes horários do dia. A altura manométrica é a energia por unidade de peso que o sistema solicita para transportar o fluido do reservatório de suç̧ão para o de descarga, com uma determinada vazão. Os outros dois parâmetros tem relação direta com o conjunto motor-bomba propriamente dito (MARRUCCI, 2009).

\section{OPORTUNIDADES PARA MELHOR EFICIÊNCIA NO SISTEMA DE BOMBEAMENTO}




\section{CONQEEESSOCIENCIAESOCIEDADE

Frente ao exposto, é possível encontrar oportunidades para melhorar a eficiência no sistema de bombeamento nas diversas etapas do processo. A primeira delas é o uso de instalações adequadas do ponto de vista da hidráulica, isto é, utilizar tubulações com diâmetro corretamente dimensionado e fazer manutenção preventiva e preditiva nas instalações. No bombeamento, já que este é o responsável pelo maior consumo de energia, é possível as seguintes ações:

- Melhorar o rendimento da bomba - através do correto dimensionamento, verificar o ponto de funcionamento e ajuste para a faixa de maior rendimento.

- Melhorar o rendimento do motor - utilizar motores de alto rendimento, realizar a manutenção das peças principalmente ventoinha, rolamentos e escovas (caso tenham), adequar o motor à bomba corretamente e evitar operações com sobrecarga.

- Reduzir a vazão recalcada - construção de reservatórios por zona de pressão, evitando que a bomba sofra falhas devido ao excesso de pressão, pois valores acima do limite especificado pela bomba hidráulica criam uma força excessiva nas engrenagens e provocam uma flexão acima do especificado, consequentemente causam danos no lado de sucção da bomba e esta perderá sua eficiência volumétrica (MARRUCCl, 2009).

- Uso de variadores de velocidade no acionamento das bombas que trabalham com diferentes cargas ao longo do dia, ajudam a reduzir o consumo de energia.

- Fazer a associação (em série, paralela ou individual) das bombas, de modo a otimizar o ponto de funcionamento do sistema.

- Eliminar o problema de cavitação. Cavitação é um fenômeno de formação de bolhas de ar que ocorre no interior dos condutos da bomba devido à diferença de pressão. Como explica Linhares (2011) esse é um efeito bastante indesejável, pois a erosão causada pela cavitação danifica de modo progressivo o rotor, a carcaça e até mesmo a tampa da bomba. 


\section{CONGEFESOCIENCIAESOCIEDADE

- Evitar a recirculação por meio da utilização de anéis de desgastes ou outros dispositivos de vedação.

Na etapa de distribuição é possível:

- Reduzir a altura manométrica;

- Reduzir a perda de carga aumentando o diâmetro das tubulações;

- Melhorar a rugosidade e diminuir a perda de carga por meio da seleção adequada dos materiais tanto da tubulação quanto dos acessórios, bem como fazer uma limpeza no interior dos tubos para evitar possíveis obstruções;

- Deslocar o consumo de energia do horário de ponta, optando pelo uso

de reservatórios nesses horários, ao invés de bombear água e ampliar a capacidade dos mesmos;

É importante frisar que todas as etapas são susceptíveis a vazamentos, logo, convém inspecionar os pontos de ligação e buscar por fissuras e rupturas nas tubulações. Além disso, é preciso substituir peças e equipamentos antigos por outros com consumo de energia mais baixo e maior rendimento, bem como respeitar a vida útil dos aparelhos. Intervenções de automação em pontos estratégicos do sistema também contribuem de forma significativa para o consumo energético do sistema.

Não se pode deixar de mencionar sobre a qualidade do fluido que está sendo bombeado. A contaminação, seja por objetos estranhos (arruelas, porcas, esferas, partes de mangueira ou vedação, entre outras) seja por partículas pequenas ou grandes (pedregulhos, areia, resíduos, etc), é o maior contribuinte para falhas de bombas hidráulicas. Elas causam ruptura de peças internas, desgaste precoce dos componentes, aquecimento, falha na isolação, problemas elétricos e pode resultar na danificação completa do equipamento.

Percebe-se que a eficiência do sistema de bombeamento, pauta-se, de modo sucinto, na prevenção de falhas através da manutenção preventiva, dimensionamento correto tanto das motor-bombas e do sistema como um todo, no ato de evitar desperdício em todas as etapas do processo incluindo o usuário final, e ainda na 


\section{cONGEFSSOCIENCIAESOCIEDADE

aquisição de equipamentos modernos com baixo consumo de energia e maior rendimento.

A ELETROBRAS/PROCEL (2005) explica que uma análise da viabilidade econômica deve analisar o valor presente líquido (calculada como a soma algébrica dos valores das entradas de caixa e dos investimentos ao longo da vida útil do projeto, de modo a verificar, caso determinado projeto seja implementado, em quanto ele será capaz de aumentar o patrimônio líquido da empresa) ou a taxa interna de retorno (quanto tempo a empresa ou investidor levará para recuperar seu capital). Essa ação deve ser efetuada, uma vez que o investimento a ser feito para alcançar a redução do consumo de energia pode, eventualmente, ser superior à economia verdadeiramente obtida.

GO Associados (2018, p.13) apresenta as propostas estabelecidas pela International Water Association (IWA) em relação aos limites eficientes para a redução de perdas, tendo em vista suas características:

\footnotetext{
- Limite econômico: volume a partir do qual os custos para reduzir as perdas são maiores que o valor intrínseco dos volumes recuperados (varia de cidade para cidade, em função das disponibilidades hídricas, dos custos de produção, etc.);

- Limite técnico ("perdas inevitáveis"): volume mínimo definido pelo alcance das tecnologias atuais dos materiais, das ferramentas, dos equipamentos e da logística.
}

Dessa forma, convém analisar também o custo com a identificação de vazamentos e a periodicidade dos reparos, visto que a empresa que investe mais em manutenção preventiva (nesse caso, técnicas para detecção de pontos de vazamentos) economiza com manutenção corretiva. Com isso, deverá ser traçado um plano estratégico de medidas que promovam a redução de custos para a empresa e diminuição do consumo hídrico-energético de modo geral.

\section{CONSIDERAÇÕES FINAIS}




\section{CONGEFESOCIENCIAESOCIEDADE \\ -}

O propósito deste trabalho foi analisar o sistema de distribuição de água, tendo em vista apontar as oportunidades de redução de custos e consumo de energia elétrica. Os resultados apontaram que a manutenção preventiva, dimensionamento correto de todos os componentes do sistema, investimentos em automatização, modernização dos equipamentos e mudança de hábitos dos usuários são fundamentais para a real economia.

O avanço da eficiência do sistema de distribuição promove ganhos econômico, social e ambiental. Por ser um estudo teórico, para trabalhos futuros, esse artigo poderá ser aprofundado e transformado em um estudo de caso por meio de pesquisa de campo, de modo a implementar as sugestões de soluções hidroenergéticas apresentadas e monitorar a redução do consumo de água e energia de determinada localidade, obtendo, assim, valores reais que fortalecem a veracidade da teoria estudada.

\section{REFERÊNCIAS}

BANCO INTERAMERICANO DE DESENVOLVIMENTO. Avaliação de Sistemas de Bombeamento de Água: Manual de Eficiência Energética. 2011. Disponível em: < https://publications.iadb.org/en/publication/16191/avaliacao-de-sistemas-debombeamento-de-agua-manual-de-eficiencia-energetica> Acesso em: 06 de set de 2019

BRASIL. Sistema Nacional de Informações sobre Saneamento: $21^{\circ}$ Diagnóstico dos Serviços de Água e Esgoto - 2015. Brasília: Ministério das Cidades, 2017.

. Agência Nacional de Águas (Brasil). Conjuntura dos recursos hídricos no Brasil 2018: informe anual. Brasília: ANA, 2018. Disponível em: < http://arquivos.ana.gov.br/portal/publicacao/Conjuntura2018.pdf> Acesso em: 12 de dez de 2018.

ELETROBRÁS/PROCEL. CENTRAIS ELÉTRICAS BRASILEIRAS, FUPAI/EFFICIENTIA.

Eficiência Energética em Sistemas de Bombeamento. Rio de Janeiro: Eletrobrás, 2005.

GIL, A. Como elaborar projeto de pesquisa. 4. ed. São Paulo: Atlas, 2002.

GO ASSOCIADOS. Perdas De Água 2018 (SNIS 2016): Desafios Para Disponibilidade Hídrica e Avanço da Eficiência do Saneamento Básico. São Paulo: 2018. 


\section{CoNGERSSOCIENCIAESOCIEDADE}

Perdas De Água 2019 (SNIS 2017): Desafios Para Disponibilidade Hídrica e Avanço da Eficiência do Saneamento Básico. São Paulo: 2019.

GOMES, H. P. Sistemas de Abastecimento de Água: Dimensionamento Econômico e Operação de Redes Elevatórias. 3. ed. João Pessoa: UFPB, 2009.

LINHARES, A. D. Observação do fenômeno de cavitação e do desgaste de rotores de latão de bombas centrífugas em instalação experimental. Dissertação (Mestrado em Engenharia dos Materiais). Universidade Federal de Ouro Preto, Ouro Preto, 2011. Disponível em: <http://www.repositorio.ufop.br/handle/123456789/3018> Acesso em: 12 de dez de 2018.

MARRUCCI, Indústria. Informativo Técnico №019/09: Principais deficiências em circuitos hidráulicos que ocasionam falhas em Bombas Hidráulicas. Piracicaba - São Paulo. 2009. Disponível em: < http://www.marrucci.com.br/uploads/informativos/019--PRINCIPAIS-DEFICIENCIAS-CIRCUITOS-HIDRAULICOS-OCASIONAM-FALHAS-BOMBASHIDRAULICAS.pdf> Acessado em: 16 de dez. de 2018. 